\title{
Oxidative stress and DNA damage in peripheral blood mononuclear cells from normal, obese, prediabetic and diabetic persons exposed to adrenaline in vitro
} \author{
Zoran Stanimirović ${ }^{\mathrm{a}}$

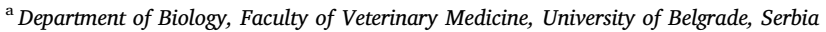 \\ ${ }^{\mathrm{b}}$ Department of Chemistry, Faculty of Veterinary Medicine, University of Belgrade, Serbia \\ ${ }^{\mathrm{c} C l i n i c}$ for Endocrinology, Diabetes and Metabolic Diseases, Clinical Center of Serbia, Belgrade, Serbia \\ ${ }^{\mathrm{d}}$ Department of Economics and Statistics, Faculty of Veterinary Medicine, University of Belgrade, Serbia \\ ${ }^{\mathrm{e}}$ School of Medicine, University of Belgrade, Serbia \\ ${ }^{\mathrm{f}}$ Institute of Pharmacology and Toxicology, University of Würzburg, Würzburg, Germany
}

Ninoslav Djelić ${ }^{a, *}$, Milena Radakovića,*, Sunčica Borozan ${ }^{\mathrm{b}}$, Vesna Dimirijević-Srećkovićc Nevena Pajovićc , Branislav Vejnović ${ }^{\mathrm{d}}$, Nevena Borozan ${ }^{\mathrm{e}}$, Ezgi Eylül Bankoglu ${ }^{\mathrm{f}}$, Helga Stopper ${ }^{\mathrm{f}}$,

\section{A R T I C L E I N F O}

\section{Keywords:}

Diabetes

Oxidative stress

DNA damage

PBMC

Adrenaline

\begin{abstract}
A B S T R A C T
Diabetes represents one of the major health concerns, especially in developed countries. Some hormones such as the stress hormone adrenaline can induce reactive oxygen species (ROS) and may worsen the diabetes. Therefore, the main aim of the investigation was to find out whether peripheral blood mononuclear cells (PBMCs) from normal persons have less DNA damage induced by adrenaline $(0.1,1$ and $10 \mu \mathrm{M})$ in comparison to PBMCs from obese, prediabetic and diabetic patients. Also, the biochemical parameters of oxidative stress (TBARS, catalase) and lactate dehydrogenase were monitored. It was observed that higher concentrations of adrenaline ( 1 and $10 \mu \mathrm{M}$ ) induced DNA damage in the obese, prediabetic and diabetic groups. In healthy individuals only the highest concentration of adrenaline caused significant increase in the DNA damage. In summary, total comet score (TCS) comparison has shown significant differences between groups, and DNA damaging effects of adrenaline were most evident in diabetic patients. The results of the biochemical analysis also demonstrate that adrenaline exerts most obvious effects in diabetic individuals which is manifested as significant change of parameters of oxidative stress. In summary, the obtained results demonstrated that diabetics are more sensitive to genotoxic effects of adrenaline and this effect probably resulted from decreased antioxidative defence mechanisms in various stages of progression through diabetes. Therefore, these results could contribute to a better understanding of a role of endocrine factors to damage of cellular biomolecules which could be useful in finding novel therapeutic approaches and lifestyle changes with an aim to lower the possibility of diabetes complications.
\end{abstract}

\section{Introduction}

Diabetes mellitus is a group of metabolic diseases characterised by hyperglycemia due to a defect in insulin secretion or/and due to a defect in its effects. International Diabetes Federation (IDF) has described diabetes as global epidemic. The most prevalent form of diabetes is type 2 diabetes mellitus (T2DM) and it is expected to increase to 439 million by 2030 [1]. One of the important factors which contribute

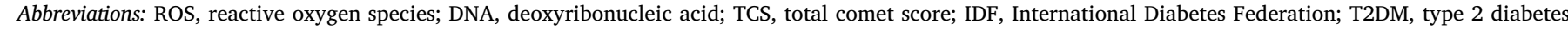

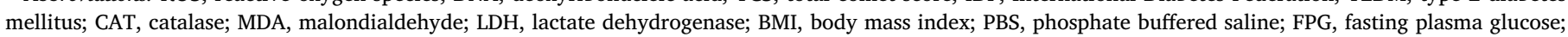
EDTA, ethylenediaminetetraacetic acid; LMPA, low melting point agarose; DMSO, dimethyl sulfoxide; TBARS, thiobarbituric acid reactive substances

* Corresponding author at: Department of Biology, Faculty of Veterinary Medicine, University of Belgrade, Oslobodjenja Blvd 18, 11000, Belgrade, Serbia.

E-mail addresses: ndjelic@vet.bg.ac.rs (N. Djelić), mj.radakovic@gmail.com (M. Radaković), sborozan@vet.bg.ac.rs (S. Borozan), vesnadsendo@gmail.com (V. Dimirijević-Srećković), nevenapajovic1992@gmail.com (N. Pajović), branislawejnovic@gmail.com (B. Vejnović), nevena.borozan@yahoo.com (N. Borozan), ezgi.bankoglu@uni-wuerzburg.de (E.E. Bankoglu), stopper@toxi.uni-wuerzburg.de (H. Stopper), zoran@vet.bg.ac.rs (Z. Stanimirović).
} 
to an increased development of T2DM is obesity [2].

Free radicals are formed during normal metabolic processes of biosynthesis, biodegradation and biotransformation and they have numerous physiological roles, such as: taking part in cell signaling, defense against infective agents, regulation of gene expression [3]. If their production is uncontrolled and overruns antioxidative capacity of the cell, a pathological state arises, followed by oxidation of membrane lipids, cell proteins and DNA. This state may result in production of new cytotoxic ROS and even the cell death [4]. In diabetic cells, the amount of glucose oxidized in the Krebs tricarboxylic acid cycle is increased, leading to an increase in generation of reactive oxygen species (ROS) and resulting oxidative stress plays a key role in the pathogenesis and progression of diabetes and diabetic complications [5].

Hyperglycemia induces excessive production of superoxide anion in electron transport chain, leading to a numerous metabolic abnormalities and activation of pathways involved in pathogenesis of diabetes complications [6].

Relatively high concentrations of $\mathrm{H}_{2} \mathrm{O}_{2}$ are released at the site of any kind of inflammation, but also in uninflammed cells (fibroblasts, endothelial cells, chondrocytes) under the influence of cytokines such as interleukin- 1 and TNF- $\alpha$. Cells are protected from hydrogen peroxide by powerful enzyme systems such as catalase in peroxisomes and glutathione peroxidase in mitochondrion's [7].

Catalase is an enzyme with high expression in all tissues. Early and profound oxidative stress in any organ, especially in pancreas, leads to, probably compensatory, increase of the activity of antioxidative enzymes including catalase [8].

If the hydrogen peroxide is not removed by catalase it can react with ferric ions (the Fenton reaction) making the more potent hydroxyl radical. This radical causes mitochondrial membrane damage in situ leading to loss of ATP production, damage to DNA, cell membrane by modification of membrane proteins, lipid peroxidation and possibly irreversible cell destruction. [9].

Accumulating evidence clearly indicates an association between oxidative stress and T2DM [10]. It has been reported that T2DM patients show higher oxidative stress which is reflected in significant changes in parameters of oxidative stress compared to healthy individuals [11]. Also significant raises in DNA damage of PBMCs in diabetic patient have been observed [11]. It is interesting that oxidative stress already exist in prediabetic patients [12]. Therefore, oxidative stress is thought to play an important role in the progression of diabetes and its complications such as foot ulcers, myocardial infarction or cerebrovascular accidents [13].

Adrenaline is a hormone and neurotrasmitter with primary roles in mobilization of resources in response to emotional and physical stress. It is also an important regulator of insulin secretion [14]. Adrenaline is used as an emergency treatment for cardiac arrest, in the treatment of asthma, allergic reactions and glaucoma [15]. There are reports which suggest that administration of adrenaline exerts genotoxic effect via ROS [16]. Moreover, short term (less than $30 \mathrm{~min}$ ) exposure of murine $3 \mathrm{~T} 3$ cells to stress hormones (including the adrenaline) causes 5 fold increase in the DNA damage revealed by the Comet assay [17]. One of the possible mechanisms of elevated ROS is achieved through stimulation of $\beta_{2}$ adrenergic receptors [18]. In addition, adrenaline may undergo autoxidation and form quinone and semiquinone that enter in redox cycling which results in excess level of ROS and lead to oxidative stress [19].

Based on the above, we hypothesize that PBMCs of prediabetic and diabetic individuals may be more sensitive to the DNA damaging effect of adrenaline and oxidative stress which may result in worsening diabetes control. In order to investigate our hypothese, we determined the genotoxic effects and as parameters of oxidative stress catalase (CAT), thiobarbituric acid reactive substances (TBARS) and lactate dehydrogenase (LDH) after administration of adrenaline in cells from healthy, obese, prediabetic and diabetic persons. To our knowledge, this type of study has not been conducted yet and the observed results may contribute to better understanding the significance of adrenaline in progression of T2DM.

\section{Material and methods}

\subsection{Study subjects}

The present study was conducted on 28 females from 46 to 63 years old $(7$ persons in each group with the following mean \pm SEM age: healthy $53.0 \pm 3.6$; obese $61.0 \pm 1.4$; prediabetes $53.8 \pm 2.3$; T2DM $57.0 \pm 2.9$ ), who attended the Department of Endocrinology, Diabetes and Metabolic Diseases in Belgrade. Neither of the subjects had been ever diagnosed with malignancy, myocardial infarction, cerebrovascular insult or any other serious complication of diabetes. All of them were non-smokers, under no medication (except for drugs for controlling blood sugar level), and without use of any food supplements. All participants were informed about the procedure of the study and signed a written consent which was approved by the Ethical committee at the Faculty of Pharmacy (University of Belgrade).

Participants were divided into four groups $(7$ females in each group): female individuals with normal blood glucose levels (healthy group); group with normal blood glucose levels and body mass index $(\mathrm{BMI}) \geq 30.0 \mathrm{~kg} / \mathrm{m}^{2}$ (obese group); group with impaired fasting plasma glucose $(5.5 \mathrm{mmol} / \mathrm{L}<$ FPG $<7 \mathrm{mmol} / \mathrm{L})$ (prediabetic group) - according to the recommendations of the World Health Definition, Diagnosis and Classification of Diabetes Mellitus and its Complications [20] and group selected on the basis of having been diagnosed with T2DM previously using an oral glucose tolerance test and/or being on antihyperglycaemic medication (diabetic group). All subjects were completely physically examined in the morning after an overnight fast. Some antropometric parameters (body height, body weight, blood pressure) were measured the same morning, and body mass index was calculated as weight in $\mathrm{kg}$ per square meters of height $\left(\mathrm{m}^{2}\right)$. Fasting plasma glucose (FPG) was determined by PAP enzymatic spectrophotometry at $505 \mathrm{~nm}$, whereas glycosylated hemoglobin (HbA1c) was determined by capilary electrophoresis on Capillarys 3 Tera device.

\subsection{Sampling and cell preparation}

Blood samples were withdrawn by venipuncture from female donors. All samples within one group were taken on the same day, and all tested parameters were done on fresh samples. The blood was diluted (1:1) with RPMI medium, underlaid with Histopaque 1077 and centrifuged at $1900 \mathrm{~g}$ for $15 \mathrm{~min}$. The PBMCs layer (buffy coat) was washed twice in RPMI 1640 medium, each wash was followed by centrifugation for $10 \mathrm{~min}$ at $1800 \mathrm{~g}$.

\subsection{Comet assay}

The alkaline version of Comet assay was performed according to Singh et al. [21] and Tice et al. [22] with minor modifications. Briefly, a suspension of isolated PBMCs in PBS was treated with adrenaline (0.1, 1 , and $10 \mu \mathrm{M}$, CAS No. 51-43-4) for $30 \mathrm{~min}$ at $37^{\circ} \mathrm{C}$. Immediatelly after the incubation period, the cell viability was checked by Trypan blue exclusion [23]. Each experiment included a positive control $(100 \mu \mathrm{M}$ $\mathrm{H}_{2} \mathrm{O}_{2}$ ) and negative control (untreated cells). After incubation, $100 \mu \mathrm{L}$ of cell suspension was mixed with $100 \mu \mathrm{L}$ of $1 \%$ low melting point agarose (LMPA). $90 \mu \mathrm{L}$ of suspension was casted on a microscope slide precoated with $1 \%$ normal melting agarose and put in the fridge to solidify. Then the slides were immersed in cold lysis solution at $\mathrm{pH} 10$ (2.5 M NaCl, $100 \mathrm{mM}$ EDTA, $10 \mathrm{mM}$ Tris $\mathrm{pH} 10,1 \%$ Triton $\mathrm{X}-100,10 \%$ DMSO) overnight at $4{ }^{\circ} \mathrm{C}$. After lysis, slides were placed in a horizontal gel electrophoresis tank to allow DNA unwinding in cold electrophoresis buffer ( $300 \mathrm{mM} \mathrm{NaOH}, 1 \mathrm{mM}$ EDTA, $\mathrm{pH}>13$ ) for $30 \mathrm{~min}$. Electrophoresis was carried out at $4^{\circ} \mathrm{C}$ with electric current of $25 \mathrm{~V}(1.1 \mathrm{~V} /$ $\mathrm{cm}$ ) for $30 \mathrm{~min}$. The slides were then removed from the tray and washed 


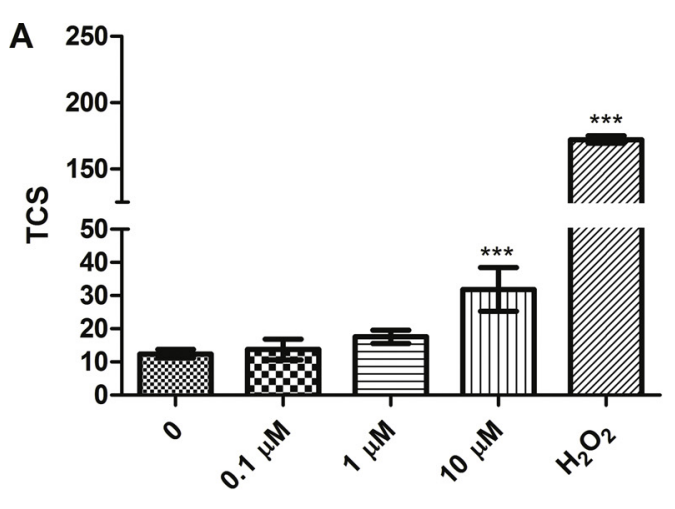

concentrations of adrenaline

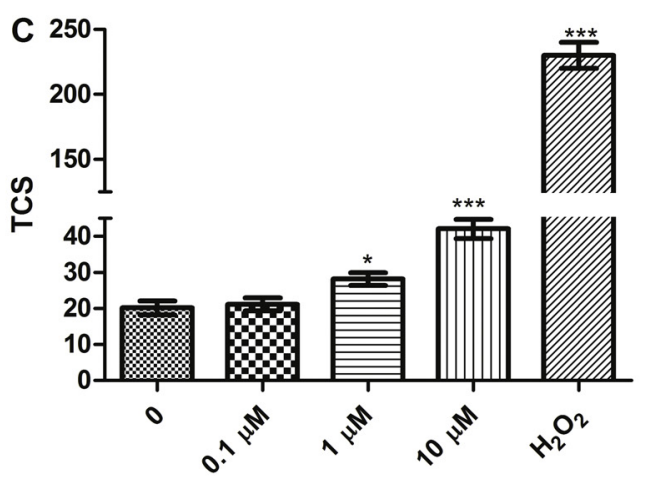

concentrations of adrenaline

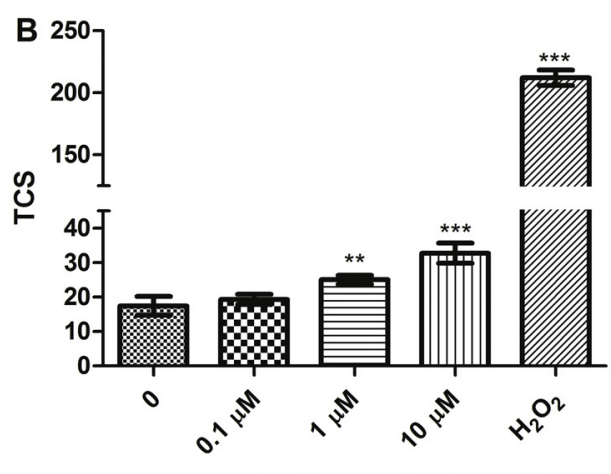

concentrations of adrenaline

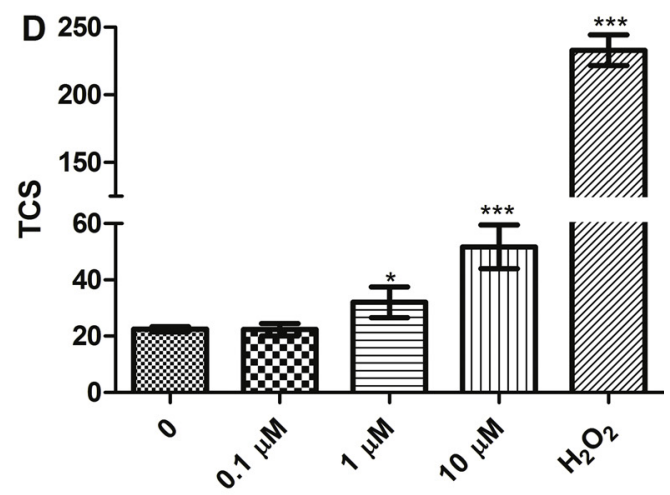

concentrations of adrenaline

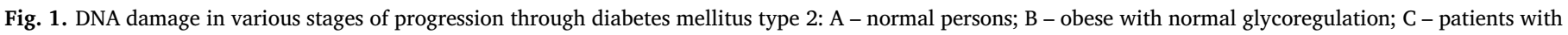
prediabetes; D - patients with type 2 diabetes mellitus (T2DM). TCS - total comet score. ${ }^{*} p<0.05$; ${ }^{* *} p<0.01$; ${ }^{* * *} p<0.001$ (Bonferroni test).

with neutralizing buffer (0.4 M Tris $\mathrm{HCl}, \mathrm{pH} 7.5)$ for 5 min. The neutralisation was repeated three times. Finally, the slides were fixed with ice cold methanol, dried and stored. Before analysis, the slides were rehydrated with ice cold distilled water and stained with ethidium bromide $(20 \mu \mathrm{g} / \mathrm{mL})$. The slides were examined under a fluorescence microscope (AxioImager Z1, Carl Zeiss; excitation filter, $515-560 \mathrm{~nm}$; emission filter, $590 \mathrm{~nm}$ ). Comet were scored visually as described by Anderson et al. [24] and expressed as the total comet score (TCS) according to Collins [25]. In visual scoring the estimated level of DNA damage results in five classes of comets: (A) no damage, $<5 \%$; (B) low level damage, 5-20\%; (C) medium level damage, 20-40\%; (D) high level damage, 40-95\%; (E) total damage, > 95\% (,hedgehogs comets"). (Fig.1). TCS is calculated according to the formula:

$\mathrm{TCS}=1 \times \mathrm{B}+2 \times \mathrm{C}+3 \times \mathrm{D}+4 \times \mathrm{E}$

where $\mathrm{B}$ to $\mathrm{E}$ represents percentage of cells with various level of DNA damage.

\subsection{Determination of catalase (CAT)}

Catalase activity was assayed in suspension of isolated PBMCs in PBS after treatment with adrenaline using $\mathrm{H}_{2} \mathrm{O}_{2}$ as substrate and activity was followed by measuring the decrease in absorbance at $240 \mathrm{~nm}$ [26]. The enzyme activity was expressed in $\mathrm{U} / \mathrm{mL}$. Each experiment included a positive control $\left(100 \mu \mathrm{M} \mathrm{H}_{2} \mathrm{O}_{2}\right)$ and negative control (untreated cells).

\subsection{Determination of lipid peroxidation (TBARS)}

Lipid peroxidation was assessed in suspension of isolated PBMCs in PBS after treatment with adrenaline, by measuring thiobarbituric acid reactive substances test (TBARS) according to the methods described by Gutteridge [27] and Traverso et al. [28]. The assay evaluated the formation of a colored adduct after the stoichiometric reaction between thiobarbituric acid (TBA) and several lipid derived aldehydes, including malondialdehyde (MDA). The TBARS level released in the samples was measured at $535 \mathrm{~nm}$. The results were expressed in $\mathrm{nmol} / \mathrm{mL}$. Each experiment included a positive control $\left(100 \mu \mathrm{M} \mathrm{H}_{2} \mathrm{O}_{2}\right)$ and negative control (untreated cells).

\subsection{Determination of lactate dehydrogenase ( $L D H)$}

After the incubation period with adrenaline, the suspension of PBMCs in PBS was centrifugated for $5 \mathrm{~min}$ at $2000 \mathrm{rpm}$ and extracellular LDH determined in the supernatant. Each experiment included a positive control $\left(100 \mu \mathrm{M} \mathrm{H}_{2} \mathrm{O}_{2}\right)$ and a negative control (untreated cells). Lactate dehydrogenase was determined by specrophotometry. The reaction solution $(2.0 \mathrm{ml})$ containing Tris $\mathrm{HCl}$ buffer $(61.43 \mathrm{mM}$, $\mathrm{pH} 7.4)$ and $\mathrm{NADH}(0.18 \mathrm{mM})$ was supplemented with pyruvate $(0.6 \mathrm{mM})$. The $100 \mu \mathrm{l}$ of the supernatant was then added in reaction solution. The extinction was detected at $339 \mathrm{~nm}$ after $30 \mathrm{~s}, 1,2$ and $3 \mathrm{~min}$ at $25^{\circ} \mathrm{C}$ [29]. The enzyme activity was expressed in $\mathrm{U} / \mathrm{mL}$. 
Table 1

Basic characteristics of the study groups.

\begin{tabular}{|c|c|c|c|c|}
\hline Parameters & Normal & Obese & Prediabetics & T2DM \\
\hline Age (years) & $53.00 \pm 3.54$ & $61.00 \pm 1.41$ & $53.83 \pm 2.27$ & $57.00 \pm 2.94$ \\
\hline FPG (mmol/L) & $5.16 \pm 0.30$ & $5.30 \pm 0.22$ & $5.57 \pm 0.17$ & $5.45 \pm 0.33$ \\
\hline HbA1c (\%) & $5.68 \pm 0.16$ & $6.05 \pm 0.29$ & $5.70 \pm 0.11$ & $6.05 \pm 0.19$ \\
\hline BM (kg) & $70.78 \pm 9.72$ & $84.65 \pm 2.96$ & $85.30 \pm 8.77$ & $78.75 \pm 6.65$ \\
\hline $\mathrm{BH}(\mathrm{cm})$ & $165.20 \pm 2.52$ & $167.00 \pm 2.74$ & $165.67 \pm 4.12$ & $175.50 \pm 3.84$ \\
\hline BMI $\left(\mathrm{kg} / \mathrm{m}^{2}\right)$ & $26.16 \pm 3.46$ & $30.4 \pm 0.27$ & $30.77 \pm 2.40$ & $25.40 \pm 1.27$ \\
\hline Systolic BP (mmHg) & $124.00 \pm 4.00$ & $132.50 \pm 10.31$ & $121.67 \pm 9.10$ & $122.50 \pm 2.50$ \\
\hline Dyastolic BP (mmHg) & $82.00 \pm 2.00$ & $82.50 \pm 4.79$ & $76.67 \pm 5.58$ & $80.00 \pm 0.00$ \\
\hline
\end{tabular}

The results are presented as mean \pm SE; FPG- fasting plasma glucose; BM - body mass; BH- body height; BMI - body mass index; BP- blood pressure. There were no statistically significant differences among groups for any analysed parameter ( $p>0.05$ in one-way ANOVA and Tukey's test).

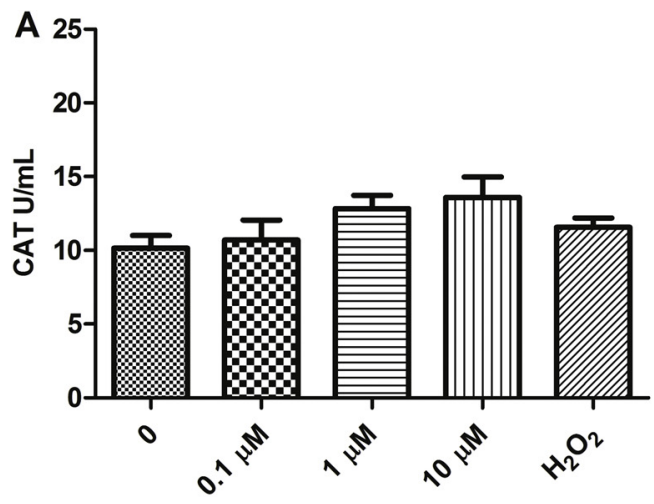

concentrations of adrenaline

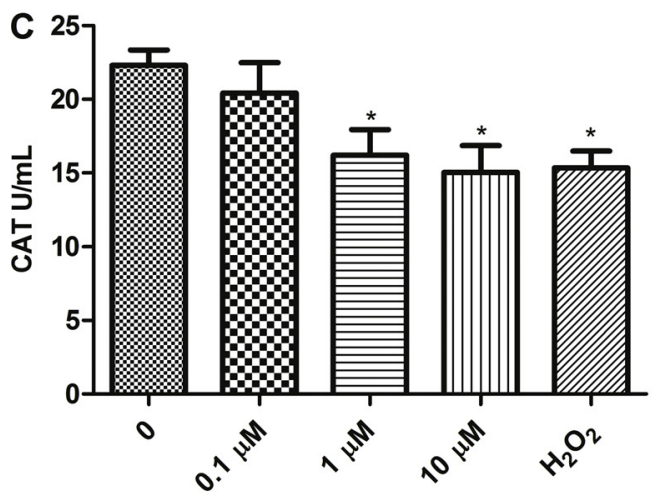

concentrations of adrenaline

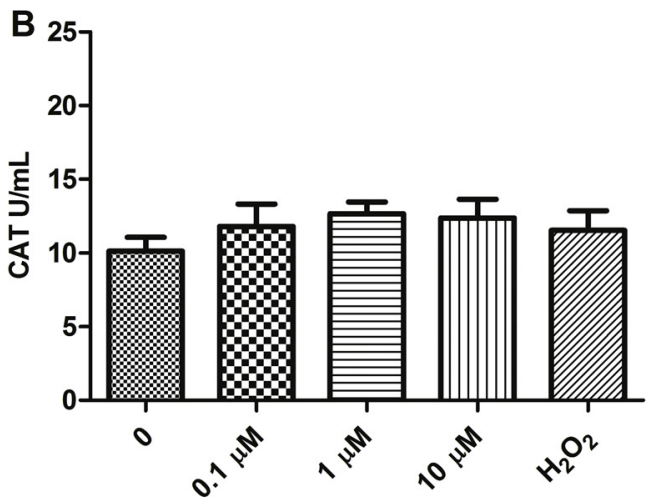

concentrations of adrenaline

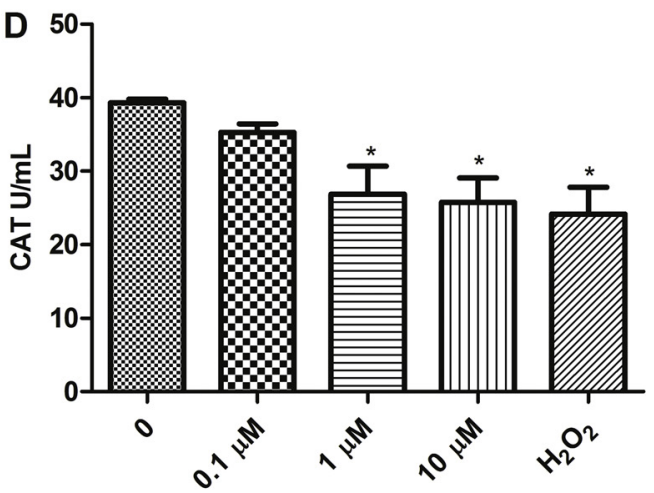

concentrations of adrenaline

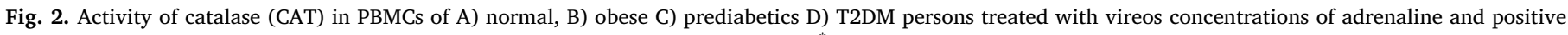

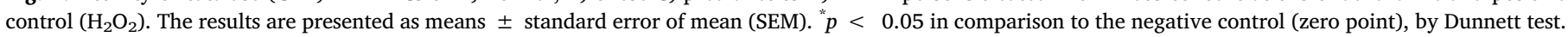

\subsection{Statistical analysis}

Due to the homogeneity of the data obtained in the Comet assay (coefficient of variation $<30 \%$ ), one-way analysis of variance (ANOVA) was used, followed by Bonferroni test. Basic antropometric and biochemical analysis among groups were analysed by one-way ANOVA and Tukey's test. Statistical significance of the differences of catalase, TBARS and LDH was determined by means of the ANOVA test followed by Dunnett test. The area under the curve (AUC) was calculated with baseline adjusted for all groups and parameters, followed by Kruskall-Wallis and Dunn`s test for heterogenous dateset, while for homogeneous dataset we used one-way ANOVA and post hoc Tukey's test. Statistical analysis was performed with GraphPad Prism version 6 (GraphPad, San Diego, CA, USA). All values are presented as the mean \pm SE. A $p$ value of less than 0.05 was considered to be statisticaly significant.

\section{Results}

The basic clinical characteristics of study groups are shown in Table 1. The groups were homogenous for all parameters (age, FPG, HbA1c, blood pressure, BMI). Homogenous results for FPG and HbA1c demonstrate that all subjects had good glycaemic control, which was supported by medication in prediabetics and diabetics. Also, none of the subjects involved in this study had a history of some serious medical condition connected to diabetes complications (stroke, heart attack, cancer, absence of any systemic disease or infection in previous months).

At all experimental points, the cell viability in Trypan blue exclusion test was acceptable (over 85\%). The results of primary DNA 


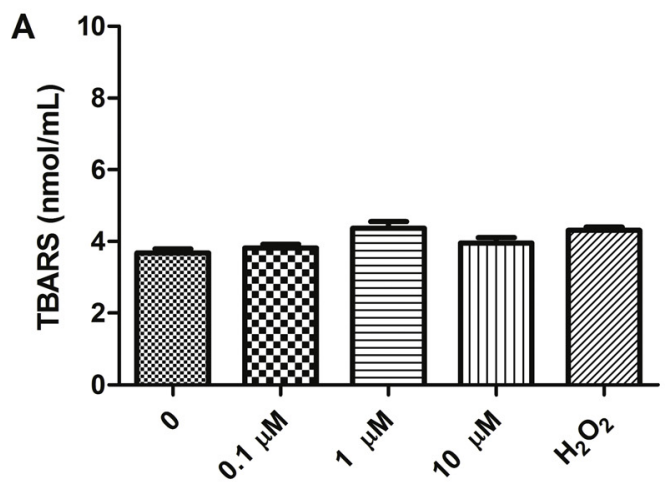

concentration of adrenaline

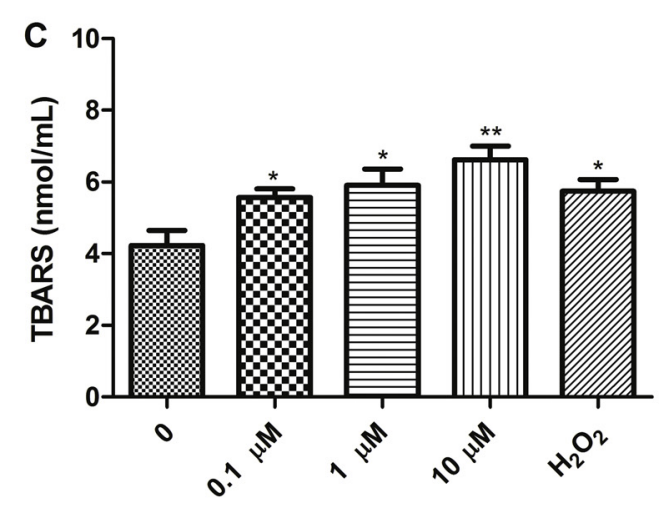

concentration of adrenaline

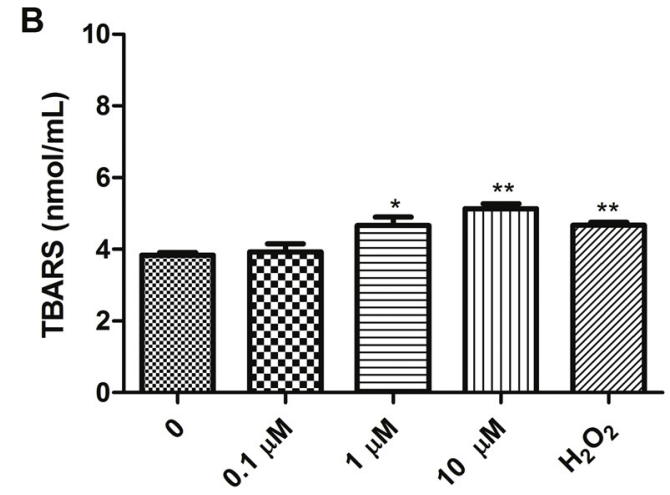

concentration of adrenaline

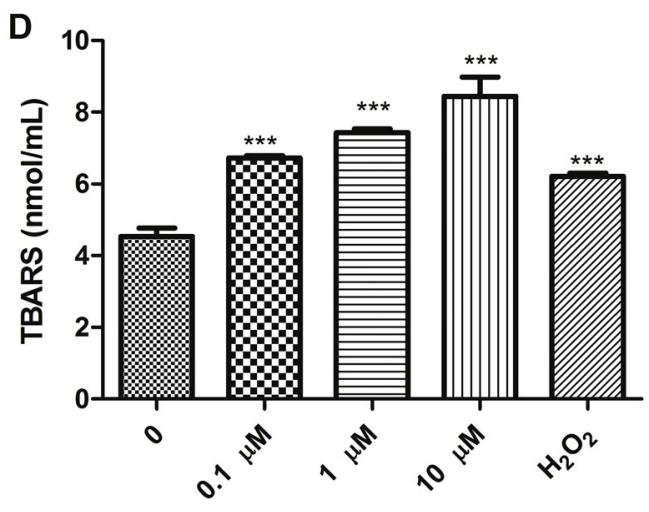

concentration of adrenaline

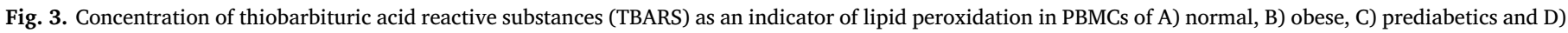

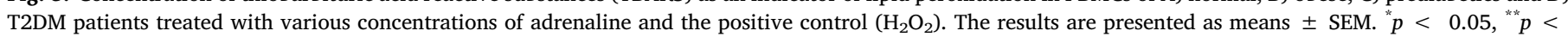
$0.01 ;{ }^{* * *} p<0.001$ in comparison to the negative control, by Dunnett test.

damage in various groups (healthy, obese, prediabetics and T2DM patients) are presented in Fig. 1. In healthy individuals only the highest concentration of adrenaline $(10 \mu \mathrm{M})$ exerted significant increase $(\mathrm{p}<0.001)$ in DNA damage which is reflected in higher value of TCS score compared to untreated cells (A). However, in PBMCs of obese individuals significant increase in DNA damage was noted at $1 \mu \mathrm{M}$ ( $\mathrm{p}<0.01$ ) and $10 \mu \mathrm{M}$ concentration of adrenaline ( $\mathrm{p}<0.001$ ), (B). Similar results were observed in the prediabetic and T2DM groups were $1 \mu \mathrm{M}$ of adrenaline induce significant rise $(\mathrm{p}<0.05)$ in DNA migration, while the highest concentration of adrenaline $(10 \mu \mathrm{M})$ caused an obvious DNA damaging effect ( $\mathrm{p}<0.001$ ) compared to untreated cells (C,D). As expected, in all tested groups the positive control $(100 \mu \mathrm{M}$ $\mathrm{H}_{2} \mathrm{O}_{2}$ ) caused highly significant DNA damage ( $\left.\mathrm{p}<0.001\right)$ in PBMCs. In summary, the basic difference in reactivity to adrenaline among the investigated groups is noticed at its concentration of $1 \mu \mathrm{M}$ since PBMCs from normal persons did not have increased TCS score, whereas PBMCs from all other groups had at least slightly significant increase of TCS score. Interestingly, 10 -fold higher concentration of adrenaline $(10 \mu \mathrm{M})$ caused highly significant DNA damage in all groups of analysed persons.

The results of catalase activity are presented on Fig. 2. There was a statistically significant decrease of catalase activity in PBMCs from prediabetics and T2DM patients after the treatment with high concentrations of adrenaline ( 1 and $10 \mu \mathrm{M})$ in comparison to the negative control. Namely, the activity of the enzyme was lowered by $27.40 \%$ and $32.56 \%(\mathrm{p}<0.05)$ in prediabetics, while $31.68 \%$ and $34.50 \%$ ( $p<0.05$ ) in diabetic patients. Roughly the same percentage of catalase inhibition was caused by hydrogen peroxide in both groups of subjects $(\mathrm{p}<0.05)$.

In order to examine the influence of increased ROS on the level of cell membrane damage in the PBMCs of the examined subjects (normal, obese, prediabetics and T2DM), under the influence of various concentrations of adrenaline in vitro, we determined the concentrations of TBARS, as well as activity of LDH as a specific marker of cell membrane damage in PBMCs [30].

The results of the effects of various concentrations of adrenaline on cell membrane damage are presented in the Fig. 3.

In healthy person PBMCs there was a weak increase at all tested concentrations, but it did not reach statistical significance in comparison to the negative control level. In PBMCs of obese subjects there was a significant increase of membrane lipids damage at higher concentrations of adrenaline: 1 and $10 \mu \mathrm{M}(\mathrm{p}<0.05$ and $\mathrm{p}<0.01)$. The examined concentrations of adrenaline caused an increase of lipid peroxidation in prediabetics with the level of significance of $p<0.05$ ( 0.1 and $1 \mu \mathrm{M}$ adrenaline) and $\mathrm{p}<0.01(10 \mu \mathrm{M}$ adrenaline). However, in T2DM subjects all concentrations of adrenaline caused an obvious damage of membrane lipids at the level of statistical significance of $\mathrm{p}<0.001$. The concentration of TBARS was increased in comparison to the untreated PBMCs for $55.7 \%, 70.90 \%$ and $95.15 \%$ (confidence interval, CI 95\%) for increasing concentrations of adrenaline of 0.1, 1 and $10 \mu \mathrm{M}$, respectively. In summary, significant differences between the investigated groups with respect to harmful effects of adrenaline on the cell membrane were most obvious in diabetic patients. PBMCs treated with hydrogen peroxide had also damage of cell membrane, and the level of statistical significance was different: $p<0.01$ in obese, $\mathrm{p}<0.05$ in prediabetics and $\mathrm{p}<0.001$ in T2DM patients. 

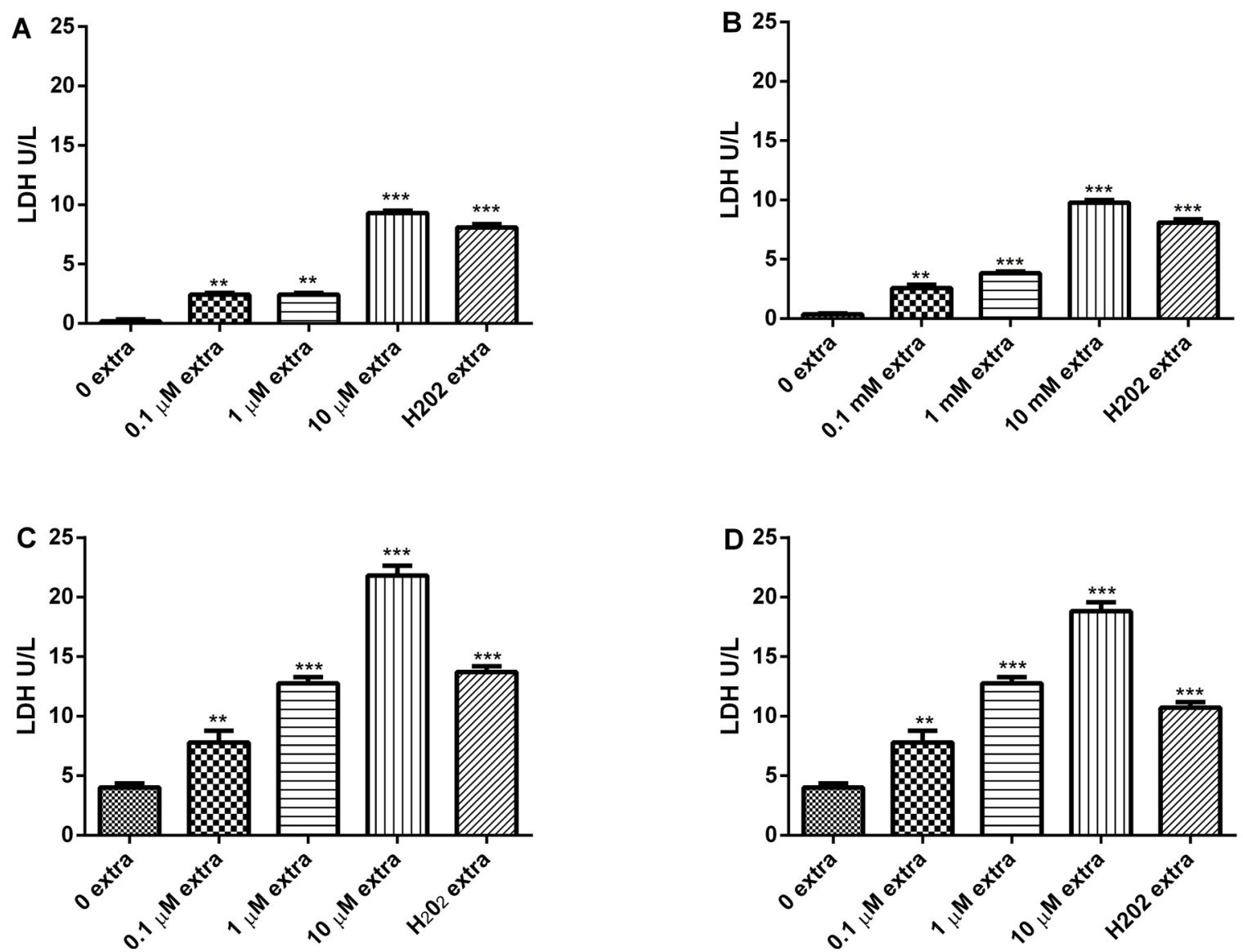

Fig. 4. Extracellular lactate dehydrogenase activity (LDH) as an indicator of cell cytotoxicity in PBMCs of A) normal, B) obese, C) prediabetics and D) T2DM, treated with various concentrations of adrenaline and positive control $\left(\mathrm{H}_{2} \mathrm{O}_{2}\right)$. The results are presented as means \pm SEM. ${ }^{* * *} p<0.01 ;{ }^{* * * *} p<0.001$ in comparison to the negative control group, by Dunnett test.

The results of the amount of released enzyme lactate dehydrogenase in all investigated groups are presented in Fig. 4.

On the basis of the amount of this enzyme we can conclude that there is a tendency of release of LDH in all groups treated with various doses of adrenaline with a high level of statistical significance. The most intensive changes are obtained in prediabetics and T2DM groups treated with concentrations of $0.1 \mu \mathrm{M}(\mathrm{p}<0.01)$ and $1 \mu \mathrm{M}$ of adrenaline $(\mathrm{p}<0.001)$, with a maximal activity at $10 \mu \mathrm{M}$ of adrenaline $(\mathrm{p}<0.001)$. The same effect was observed with $\mathrm{H}_{2} \mathrm{O}_{2}(\mathrm{p}<0.001)$.

Results of the analysis of area under the curve (AUC) for each investigated parameter are presented at the Fig. 5. On the basis of the obtained results it is obvious that total comet score (TCS) is increased $(\mathrm{p}<0.0001)$ in all investigated groups (obese, prediabetics and diabetics) when compared to normal subjects. Prediabetics and T2DM groups had increased level of cell membrane damage (AUC of TBARS, AUC of LDH) in comparison to normal and obese persons with various levels of statistical significance (Fig. 5). On the other hand, increase of AUC for CAT was observed in prediabetics ( $\mathrm{p}<0.05)$ and T2DM group ( $\mathrm{p}<0.001$ ), compared to the control and obese subjects.

\section{Discussion}

It is well established that diabetes is associated with increased production of reactive oxygen species (ROS) which is one of the most important factors for the disease progression and development of chronic complications $[11,31]$. In addition to decreased level of oxidative DNA damage, diabetics have lower capacity of antioxidative defence mechanisms [32].

In this study, we treated isolated human PBMCs with three concentrations of adrenaline $(0.1,1$ and $10 \mu \mathrm{M})$. These concentrations are much higher than therapeutic doses of adrenaline for treatment of cardiac arrest. We chose these concentrations to build on previous in vitro results that we have published [33]. All concentrations of adrenaline in our investigation were much higher than blood adrenaline in some severe pathophysiological conditions such as pheochromocytoma. However, the highest concentration of $10 \mu \mathrm{M}$ is much lower than highest possible concentration $(10 \mathrm{mM})$ recommended for in vitro Comet assay of relatively untoxic compounds [22].

It should be mentioned that dose of adrenaline depends not only on its concentration but also on the treatment duration. In our previous investigation [33] of genotoxic effects of adrenaline on PBMCs even the concentration of $0.001 \mu \mathrm{M}$ was high enough to produce significant DNA damage after $15 \mathrm{~min}$ of treatment, while after $1 \mathrm{~h}$ the concentration of 5 $\mu \mathrm{M}$ was high enough to increase DNA migration in the Comet assay. In the present investigation, an intermediate time of $30 \mathrm{~min}$ was good enough to make $1 \mu \mathrm{M}$ of adrenaline to cause a significant level of DNA damage. Therefore, at shorter time of treatment DNA damage is not repaired enough giving the increased level of DNA damage in the Comet assay.

The increased DNA damage under the influence of adrenaline was evident at a concentration of $1 \mu \mathrm{M}$ in obese, prediabetic and diabetic persons, showing that their PBMCs are more sensitive to genotoxic effects of adrenaline, despite the fact that all our subjects had good glycaemic control. Namely, impared glucose regulation causes higher level of DNA damage, especially in patients diagnosed with T2DM [34,35]. Since only normal subjects in our investigation did not respond to intermediate dose $(1 \mu \mathrm{M})$ of adrenaline in the Comet assay, even the obesity is a risk factor for increased sensitivity of PBMCs to DNA 

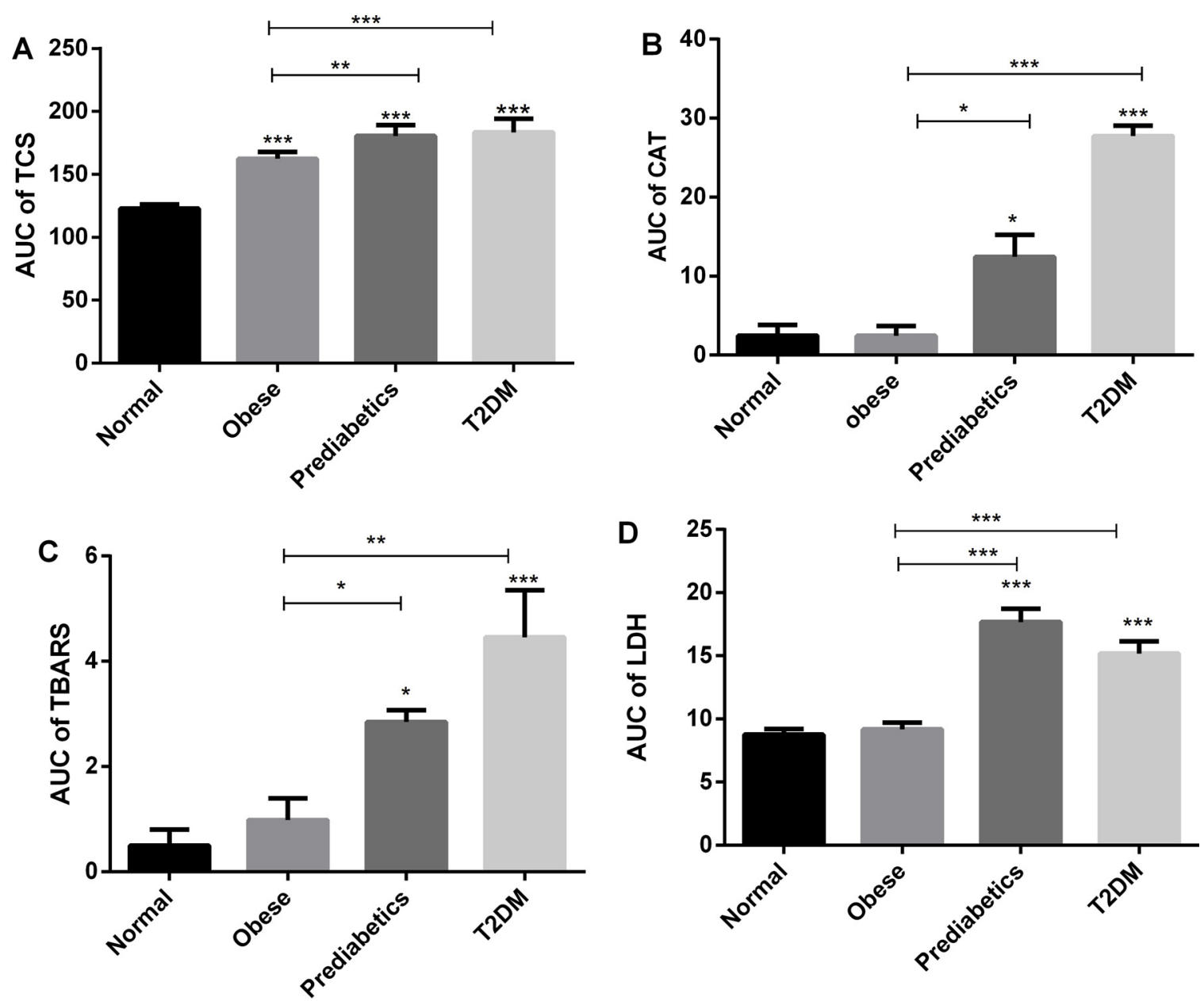

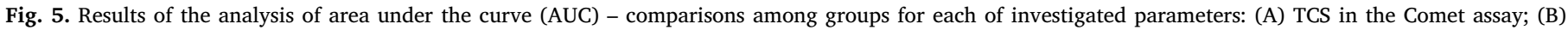
catalase; (C) TBARS and (D) LDH.

damaging effects of adrenaline. Indeed, there is an association between oxidative stress and obesity [36] and it is not surprising that obesity has contribution in the etiopathogenesis of diabetes mellitus [37].

There are experimental findings [38] that adrenaline causes greater increase of plasma glucose in obese than in non-obese mice, while plasma insulin level decreased only in obese animals after administration of adrenaline. This implies significant role of hyperglycemia in oxidative DNA damage. Indeed, there is a reduction of DNA damage after insulin treatment [39], whereas hyperglycemia may accelerate ROS through glucose oxidation pathway [40]. Bearing in mind that the T2DM group has higher blood glucose than prediabetics and obese groups it is not surprising that diabetics are most susceptible to oxidative DNA damage. This type of damage in our study is even more pronounced after adrenaline administration. Interestingly, despite harmful effects due to ROS production, adrenaline may have some beneficial effects in diabetic patients by increasing the glucagone secretion which may mitigate the sudden hypoglycemia [41] Hamilton et al., 2018).

Adrenaline caused increased DNA damage possibly by production of reactive oxygen species (ROS), as demonstrated in our previous investigations $[16,33]$. The possible mechanisms underlying this ROS production may include redox cycling of adrenaline [19] and/or stimulation of $\beta_{2}$ adrenoceptors [18].

In order to determine the effect of adrenaline on antioxidative status in all tested group we evaluated activity of CAT. Analyzing the PBMCs catalase activity, we noticed a weak increase of the activity of this enzyme in control and obese groups. A high level of catalase enables lower hydrogen peroxide production in cells and therefore prevents oxidative damage [42]. A decrease in catalase activity can be the result of inactivation of the enzyme. Decreased activity of catalase can lead to a numerous harmful effects due to accumulation of superoxide anion and hydrogen peroxide [43].

By comparison of the values between control and obese subjects, we observed a higher initial levels of activities of enzymes in prediabetic and diabetic groups. These results are in accordance with a study of Cericllo et al. [44] showing that biomarkers of oxidative stress, including the activity of catalase, are increased in T2DM patients. The hyperglycemia itself is gradually established during the period of prediabetes and it causes an additional increase of free radical production.

In this study, we showed that after the treatment of PBMCs with various concentrations of adrenaline or $\mathrm{H}_{2} \mathrm{O}_{2}$ activity of catalase is decreased. Therefore, the antioxidative capacity of the cell is lowered and production of free radicals is increased, and all of that results in redox homeostasis disorder [4].

The end products of lipid peroxidation are extremely reactive and cause a consecutive chain propagation and oxidation of nearby polyunsaturated fatty acid (PUFA). It has been shown that products of lipid peroxidation can be transported from the site of their formation to the other sites in organism, acting as secondary cytotoxic signalling molecules - signals that transfer an information about the origin of primary oxidative reaction [45]. An extent of lipid peroxidation in examined patients was monitored by concentration TBARS including of MDA, one of the end products of cyclic reaction of lipid peroxidation as a marker of oxidative damage in cells. MDA is especially important product because it has mutagenic effects in mammalian cells and carcinogenic effect in rodents [3]. Our results have shown increased levels of TBARS 
at all three concentrations of adrenaline in vitro, and in all examined groups of patients in comparison to the negative control, except for the control group. The most profound changes were detected in T2DM group, at all concentrations of adrenaline (Fig. 3). Increased TBARS were noticed in T2DM in correlation with duration of the illness and development of complications [46]. Alvarez-Diduk and Galano [47] suggest that catecholamines (adrenaline and noradrenaline) play role as protectors and molecular targets of oxidative stress.

PBMCs from T2DM patients exhibited production of ROS and damage of cell membranes [48]. Adrenaline exerts a similar effect in regard to TBARS level. In this investigation all tested concentrations of adrenaline in D2MT subjects induced significant enhancement of level of TBARS in comparison to control. In addition, the significant increase in TBARS level was found in prediabetic and T2DM group after treatment with highest concentration of adrenaline. Previous studies have reported increased levels of lipid peroxide in nonobese T2DM subject [49]. On other hand, there is evidence that treatment with adrenaline may result in significant increment of lipid peroxidation [50]. Therefore increased TBARS level significes on disrupted of redox homeostasis as result of adrenaline influence. Besides, the observed DNA damage may derive from lipid peroxidation, since MDA has the ability to react with DNA and form exocyclic adducts such as mutagenic pyrimidopurinone. Respectively, lipid peroxidation may be important mediators of DNA damage related with oxidative stress caused by reactions of adrenaline and higher level of glucose.

The PBMCs membrane damage in this study was indirectly also monitored through the amount of release of the enzyme lactate dehydrogenase from cells. LDH is a strictly intracellular enzyme, the damage of cell membranes in tissues causes leak of cytoplasmic enzyme LDH from cells. Therefore, spontaneous LDH release and the level of LDH extracellular activity can be used to estimate which tissue is damaged and to what extent [51]. In all experimental groups in this investigation, we observed increased amounts of extracellular LDH, pointing to unambiguously increased damage of PBMCs membranes.

The produced reactive oxygen species start the lipid peroxidation interacting with PUFA, which concentration is the highest in cell membranes of parenhymatic organs in T2DM [5]. That is why it is important to monitor parameters of oxidative damage such as hydrogen peroxide content, which directly give an answer about formation of hydroxyl radical that can lead to disturbed cell functioning resulting with mutagenesis and carcinogenesis [52]. However, further studies are needed to unravel the exact mechanisms underlying adrenaline induced genotoxicity.

\section{Conclusions}

PBMCs of obese, prediabetic and T2DM persons are more prone to DNA damage after in vitro treatment with adrenaline in comparison to those of healthy individuals. Also, in these groups of patients adrenaline causes a higher increase in oxidative stress and damage of cell membrane in vitro in comparison to the healthy group.

\section{Conflict of interest}

The authors declare no conflicts of interests.

\section{Acknowledgements}

This research resulted from bilateral co-operation between Germany and Serbia (supported by DAAD and Serbian Ministry of Education, Science and Technological Development [grant \#III46002]) and COST action hCOMET [CA 15132].

\section{References}

[1] L. Chen, D.J. Magliano, P.Z. Zimmet, The worldwide epidemiology of type 2 diabetes mellitus-present and future perspectives, Nat. Rev. Endocrinol. 8 (2011) 228-236, https://doi.org/10.1038/nrendo.2011.183.

[2] S. Wild, G. Roglic, A. Green, R. Sicree, H. King, Global prevalence of diabetes: estimates for the year 2000 and projections for 2030, Diabetes Care 27 (2004) 1047-1053, https://doi.org/10.2337/diacare.27.5.1047.

[3] M. Valko, D. Leibfritz, J. Moncol, M.T. Cronin, M. Mazur, J. Telser, Free radicals and antioxidants in normal physiological functions and human disease, Int. J. Biochem. Cell Biol. 39 (2007) 44-84, https://doi.org/10.1016/j.biocel.2006.07. 001.

[4] B. Halliwell, J.M. Gutteridge, Free Radicals in Biology and Medicine, 3rd ed., Oxford University press, New York, 1999.

[5] Z. Rašić-Milutinović, T. Popović, G. Peruničić-Peković, S. Borozan, D. Ristić-Medić, M. Lačković, M. Glibetić, Lower serum paraoxonase-1 activity is related to linoleic and gocosahexanoic fatty acids in type 2 diabetic patient, Arch. Med. Res. 43 (2012) 75-82.

[6] L. Rochette, M. Zeller, Y. Cottin, C. Vergely, Diabetes, oxidative stress and therapeutic strategies, Biochim. Biophys. Acta 1840 (2014) 2709-2729, https://doi. org/10.1016/j.bbagen.2014.05.017.

[7] C. Glorieux, P.B. Calderon, Catalase, a remarkable enzyme: Targeting the oldest antioxidant enzyme to find a new cancer treatment approach, Biol. Chem. 398 (2017) 1095-1108, https://doi.org/10.1515/hsz-2017-0131.

[8] A. Dabrowski, A. Gabryelewicz, Oxidative stress - an early phenomenon characteristic of acute experimental pancreatitis, Int. J. Pancreatol. 12 (1992) 193-199.

[9] A. Ayala, M.F. Muñoz, S. Argüelles, Lipid peroxidation: production, metabolism, and signaling mechanisms of malondialdehyde and 4-hydroxy-2-nonenal, Oxid. Med. Cell. Longev. 2014 (2014) 360438, https://doi.org/10.1155/2014/360438.

[10] L.A. Pham-Huy, H. He, C. Pham-Huy, Free radicals, antioxidants in disease and health, Int. J. Biomed. Sci. 4 (2008) 89-96.

[11] M. Arif, M.R. Islam, T.M.Z. Waise, F. Hassan, S.I. Mondal, Y. Kabir, DNA damage and plasma antioxidant indices in Bangladeshi Type 2 diabetic patients, Diabetes Metab. 36 (2010) 51-57, https://doi.org/10.1016/j.diabet.2009.05.007.

[12] L. Maschirow, K. Khalaf, H.A. Al-Aubaidy, H.F. Jelinek, Inflammation, coagulation, endothelial dysfunction and oxidative stress in prediabetes - biomarkers as a possible tool for early disease detection for rural screening, Clin. Biochem. 48 (2015) 581-585, https://doi.org/10.1016/j.clinbiochem.2015.02.015.

[13] I.M. Stratton, A.I. Adler, H.A.W. Neil, D.R. Matthews, S.E. Manley, C.A. Cull, D. Hadden, R.C. Turner, R.R. Holman, Association of glycaemia with macrovascular and microvascular complications of type 2 diabetes (UKPDS 35): prospective observational study, BMJ 321 (2000) 405-412, https://doi.org/10.1136/bmj.321. 7258.405 .

[14] I. Lundquist, L.E. Ericson, $\beta$-Adrenergic insulin release and adrenergic innervation of mouse pancreatic islets, Cell Tissue Res. 193 (1978) 73-85.

[15] H.P. Rang, M.M. Dale, J.M. Ritter, R.J. Flower, G. Henderson, Rang and Dale's Pharmacology, 7th edn., Elsevier Churchill Livingstone, Edinburgh, 2012.

[16] M. Radaković, N. Djelić, J. Stevanović, M. Andjelković, S. Kolarević, S. Dačić, Z. Stanimirović, The investigation of DNA damage induced by adrenaline in human lymphocytes in vitro, Acta Vet. (Beograd.) 64 (2014) 281-292, https://doi.org/10. 2478/acve-2014-0027.

[17] M.S. Flint, A. Baum, W.H. Chambers, F.J. Jenkins, Induction of DNA damage, alteration of DNA repair and transcriptional activation by stress hormones, Psychoneuroendocrinology 32 (2007) 470-479, https://doi.org/10.1016/j. psyneuen.2007.02.013.

[18] F. Sun, X.P. Ding, S.M. An, Y.B. Tang, X.J. Yang, L. Teng, C. Zhang, Y. Shen, H.Z. Chen, L. Zhu, Adrenergic DNA damage of embryonic pluripotent cells via $\beta_{2}$ receptor signalling, Sci. Rep. 5 (2015) 15950, https://doi.org/10.1038/ srep15950.

[19] A. Bindoli, D.J. Deeble, M.P. Rigobello, L. Galzigna, Direct and respiratory chainmediated redox cycling of adrenochrome, Biochim. Biophys. Acta 1016 (1990) 349-356, https://doi.org/10.1016/0005-2728(90)90168-4.

[20] K.G. Alberti, P.Z. Zimmet, Definition, diagnosis and classification of diabetes mellitus and its complications: Report of a WHO consultation. Part 1: diagnosis and classification of diabetes Mellitus provisional report of a WHO consultation, Diabet. Med. 15 (1998) 539-553, https://doi.org/10.1002/(SICI)1096-9136(199807) 15:7 < 539::AID-DIA668 > 3.0.CO;2-S.

[21] N.P. Singh, M.T. McCoy, E.L. Tice, Schneider, A simple technique for quantitation of low levels of DNA damage in individual cells, Exp. Cell Res. 175 (1988) 184-191, https://doi.org/10.1016/0014-4827(88)90265-0.

[22] R.R. Tice, E. Agurell, D. Anderson, B. Burlinson, A. Hartmann, H. Kobayashi, Y. Miyamae, E. Rojas, J.-C. Ryu, Y.F. Sasaki, Single cell gel/comet assay: guidelines for in vitro and in vivo genetic toxicology testing, Environ, Mol, Mutagen. 35 (2000) 206-221, https://doi.org/10.1002/(SICI)1098-2280(2000)35:3<206::AIDEM8 > 3.0.CO;2-J.

[23] B.L. Pool-Zobel, C. Guigas, R. Klein, C.H. Neudecker, H.W. Renner, P. Schmezer, Assesment of genotoxic effects of lindane, Food Chem. Toxicol. 4 (1993) 271-283.

[24] D. Anderson, T.W. Yu, B.J. Phillips, P. Schmezer, The effect of various antioxidants and other modifying agents on oxygen-radical-generated DNA damage in human lymphocytes in the COMET assay, Mutat. Res. 307 (1994) 261-271, https://doi. org/10.1016/0027-5107(94)90300-X.

[25] A.R. Collins, The comet assay for DNA damage and repair. Principles, applications, and limitations, Mol. Biotechnol. 26 (2004) 249-261, https://doi.org/10.1385/ $\mathrm{MB}: 26: 3: 249$.

[26] H. Aebi, Catalase in vitro, in: L. Packer (Ed.), Methods in Enzymology, Academic Press, Orlando, Florida, USA, 1984, pp. 121-126.

[27] J.M.C. Gutteridge, Lipid peroxidation and antioxidants as biomarkers of tissue damage, Clin. Chem. 41 (1995) 1819-1828.

[28] N. Traverso, S. Menini, E.P. Maineri, S. Patriarca, P. Odetti, D. Cottalasso, 
U.M. Marinari, M.A. Pronzato, Malondialdehyde, a lipoperoxidation-derived aldehyde, can bring about secondary oxidative damage to proteins, J. Gerontol. A Biol. Sci. Med. Sci. 59 (2004) B890-B895, https://doi.org/10.1093/gerona/59.9.B890.

[29] H.U. Bergmeyer, E. Brent, H.U. Bergmeyer (Ed.), Section C: Methods for Determination of Enzyme Activity, $2^{\text {nd }}$ ed., 2. Lactate dehydrogenases. Academic Press, New York, 1974.

[30] G. Fotakis, J.A. Timbrell, In vitro cytotoxicity assays: comparison of LDH, neutra red, MTT and protein assay in hepatoma cell lines following exposure to cadmium chloride, Toxicol. Lett. 160 (2006), https://doi.org/10.1016/j.toxlet.2005.07.001 177-177.

[31] M. El-Wassef, G.S.M. El-Saeed, S.E. El-Tokhy, H.M. Raslan, S. Tawfeek, I. Siam, S.I. Salem, Oxidative DNA damage in patients with type 2 diabetes mellitus, Diabetol. Croatica 41 (2012) 121-127.

[32] A. Sliwinska, J. Blasiak, J. Kasznicki, J. Drzewoski, In vitro effect of gliclazide on DNA damage and repair in patients with type 2 diabetes mellitus (T2DM), Chem. Biol. Interact. 173 (2008) 159-165, https://doi.org/10.1016/j.cbi.2008.03.017.

[33] N. Djelić, M. Radaković, B. Spremo-Potparević, L. Živković, V. Bajić, J. Stevanović, Z. Stanimirović, Evaluation of cytogenetic and DNA damage in human lymphocytes treated with adrenaline in vitro, Toxicol. In Vitro 29 (2015) 27-33, https://doi.org/ 10.1016/j.tiv. 2014.08.001.

[34] F. Song, J.I.A. Wenbo, Y. Yao, H.U. Yafei, L.E.I. Lin, J. Lin, X. Sun, L. Liu, Oxidative stress, antioxidant status and DNA damage in patients with impared glucose regulation and newly diagnosed Type 2 diabetes, Clin. Sci. 112 (2007) 599-606, https://doi.org/10.1042/CS20060323.

[35] M. Lodovici, L. Giovannelli, V. Pitozzi, E. Bigagli, G. Bardini, C.M. Rotella, Oxidative DNA damage and plasma antioxidant capacity in type 2 diabetic patients with good and poor glycaemic control, Mutat. Res. 638 (2008) 98-102.

[36] C.J. Huang, M.J. McAllister, A.L. Slusher, H.E. Webb, J.T. Mock, E.O. Acevedo, Obesity-related oxidative stress: the impact of physical activity and diet manipulation, Sports Med. Open 1 (2015) 32, https://doi.org/10.1186/s40798-0150031-y.

[37] D. Pitocco, M. Tesauro, R. Alessandro, G. Ghirlanda, C. Cardillo, Oxidative stress in diabetes: implications for vascular and other complications, Int. J. Mol. Sci. 14 (2013) 21525-21550, https://doi.org/10.3390/ijms141121525.

[38] R.S. Surwit, M.S. Schneider, M.N. Feinglos, Stress and diabetes mellitus, Diabetes Care 15 (1992) 1413-1422, https://doi.org/10.2337/diacare.15.10.1413.

[39] S. Simone, Y. Gorin, C. Velagapudi, H.E. Abboud, S.L. Habib, Mechanism of oxidative DNA damage in diabetes, Diabetes 57 (2008) 2626-2636, https://doi.org/ $10.2337 / \mathrm{db} 07-1579$.

[40] M.L. Lazo-de-la-Vega-Monroy, C. Fernández-Mejía, Oxidative stress in diabetes mellitus and the role of vitamins with antioxidant actions, Oxidative Stress and Chronic Degenerative Diseases-A Role for Antioxidants, InTech, 2013, https://doi. org $/ 10.5772 / 51788$
[41] A. Hamilton, Q. Zhang, A. Salehi, M. Willems, J.G. Knudsen, A.K. Ringgaard, C.E. Chapman, A. Gonzalez-Alvarez, N.C. Surdo, M. Zaccolo, D. Basco, P.R.V. Johnson, R. Ramracheya, G.A. Rutter, A. Galione, P. Rorsman, A.I. Tarasnov, Adrenaline stimulates glucagon secretion by Tpc2-dependent $\mathrm{Ca}_{2}{ }^{+}$mobilization from acidic stores in pancreatic $\alpha$-cells, Diabetes 67 (2018) 1128-1139, https://doi. org $/ 10.2337 / \mathrm{db} 17-1102$.

[42] S. Mukherjee, S. Ghosh, S. Choudhury, A. Adhikary, K. Manna, S. Dey, G. Sa, T. Das, S. Chattopadhyay, Pomegranate reverses methotrexate-induced oxidative stress and apoptosis in hepatocytes by modulating Nrf2-NF-kB pathways, J. Nutr. Biochem. 24 (2013) 2040-2050, https://doi.org/10.1016/j.jnutbio.2013.07.005.

[43] E.Y. Sozmen, B. Sozmen, Y. Delen, T. Onat, Catalase/superoxide dismutase (SOD) and catalase/paraoxonase (PON) ratios may implicate poor glycemic control, Arch Med. Res. 32 (2001) 283-287, https://doi.org/10.1016/S0188-4409(01)00285-5.

[44] A. Ceriello, P. dello Russo, P. Amstad, P. Cerutti, High glucose induces antioxidant enzymes in human endothelial cells in culture: evidence linking hypcrglicemia and oxidative stress, Diabetes 45 (1996) 471-477, https://doi.org/10.2337/diab.45.4. 471.

[45] K. Uchida, Histidine and lysine as targets of oxidative modification, Amino Acids 25 (2003) 249-257, https://doi.org/10.1007/s00726-003-0015-y.

[46] I. Akkus, S. Kalak, H. Vural, O. Caglayan, E. Menekse, G. Can, B. Durmus, Leukocyte lipid peroxidation, superoxide dismutase, glutathione peroxidase and serum and leukocyte vitamin C levels of patients with type II diabetes mellitus, Clin. Chim. Acta 244 (1996) 221-227, https://doi.org/10.1016/0009-8981(96)83566-2.

[47] R. Alvarez-Diduk, A. Galano, Adrenaline and noradrenaline: protectors agains oxidative stress or molecular targets? J. Phys. Chem. 119 (2015) 3479-3491, https://doi.org/10.2021/acs.jpcb.5b00052.

[48] S. Belia, F. Santilli, S. Beccafico, L. De Feudis, C. Morabito, G. Davi, G. Fanò, M.A. Mariggiò, Oxidative-induced membrane damage in diabetes lymphocytes: effects on intracellular $\mathrm{Ca}^{2+}$ homeostasis, Free Radic. Res. 43 (2009) 138-148, https://doi.org/10.1080/10715760802629588.

[49] V.K. Khemka, D. Bagchi, A. Ghosh, O. Sen, A. Bir, S. Chakrabarti, A. Banerjee, Raised serum adenosine deaminase level in nonobese type 2 diabetes mellitus, Sci. World J. (2013) 5, https://doi.org/10.1155/2013/404320 ID 404320.

[50] B. Romana-Souza, G.S. Lima-Cezar, A. Monte-Alto-Costa, Psychological stress-in duced catecholamines accelerates cutaneous aging in mice, Mech. Ageing Dev. 152 (2015) 63-73, https://doi.org/10.1016/j.mad.2015.10.004.

[51] A. Cabarkapa, S. Borozan, L. Zivkovic, S. Stojanovic, M. Milanovic-Cabarkapa, V. Bajic, B. Spremo Potparevic, $\mathrm{CaNa}_{2}$ EDTA chelation attenuates cell damage in workers exposed to lead - a pilot study, Chem. Biol. Interact. 242 (2015) 171-178, https://doi.org/10.1016/j.cbi.2015.10.002.

[52] J.M. Dzik, Molecules released by helminth parasites involved in host colonization, Acta Biochim. Polon. 53 (2005) 33-64. 